\title{
Correction to: Apis mellifera hemocytes generate increased amounts of nitric oxide in response to wounding/ encapsulation
}

\author{
Pedro Negri ${ }^{1,3,5}$, Silvina QuintanA ${ }^{4}$, Matias MagGI ${ }^{1,3}$, Nicolas Szawarski ${ }^{1}$, \\ Lorenzo Lamattina $^{2,3}$, Martin Eguaras ${ }^{1,3}$ \\ ${ }^{1}$ Laboratorio de Artrópodos, Facultad de Cs Exactas y Naturales, Universidad Nacional de Mar del Plata (UNMdP), Mar \\ del Plata, Argentina \\ ${ }^{2}$ Instituto de Investigaciones Biológicas-CONICET, Universidad Nacional de Mar del Plata, Mar del Plata, Argentina \\ ${ }^{3}$ Consejo Nacional de Investigaciones Científicas y Téenicas (CONICET), Buenos Aires, Argentina \\ ${ }^{4}$ Laboratorio de Biología Molecular, Fares Taie Instituto de Análisis, Mar del Plata, Argentina \\ ${ }^{5}$ Funes 3350, Facultad de Cs Exactas y Naturales, nivel 0, 7600, Mar del Plata, PC, Argentina
}

Received 7 December 2018 - Accepted 17 June 2019

\section{Correction to: Apidologie (2014) 45:610-617 \\ https://doi.org/10.1007/s13592-014-0279-0}

This correction stands to correct the last sentence found in the caption of Figure 2 where it reads, "Three independent experiments were performed and a total of 18 larvae per treatment were analyzed." By request of the author group, this should instead read, "Three independent experiments were performed and a total of 18 larvae $(9$ per treatment) were analyzed." With attention to this, the original article is corrected with no changes to the original findings in the original article. The original article has been corrected.

Publisher's note Springer Nature remains neutral with regard to jurisdictional claims in published maps and institutional affiliations.

Corresponding author: P. Negri, pedronegri1@yahoo.com.ar M. Eguaras and L. Lamattina contributed equally as senior authors.

Manuscript editor: Klaus Hartfelder

The online version of the original article can be found at https://doi.org/10.1007/s13592-014-0279-0 